\title{
Technology of a dietary supplement "SoleVit Mg" based on Salicornia Europaea L. for use in food technologies
}

\author{
Victoria Evlash, Natalia Murlykina*, Olena Aksonova, and Liudmyla Hazzavi-Rogozina \\ ${ }^{1}$ Kharkiv State University of food technology and trade, 61051, Kharkiv, Ukraine
}

\begin{abstract}
On the basis of the above-ground part of the plant samples of Salicornia Europaea, technologies of the dietary supplement "SoleVit Mg" and frozen semi-finished products for use in food technologies have been developed. It has been experimentally confirmed that they contain all groups of basic nutrients - proteins, fats and carbohydrates, are a source of valuable vitamins (choline, nicotinic acid, vitamin $\mathrm{C}, \beta$-carotene, etc.) and mineral elements, have an increased content of sodium chloride, have antioxidant activity. Sodium $-3460 \mathrm{mg}$, potassium $-1155 \mathrm{mg}$, magnesium $-770 \mathrm{mg}$, calcium $-580 \mathrm{mg}$, phosphorus $-650 \mathrm{mg}$, silicon $-80 \mathrm{mg}$, zinc $11.5 \mathrm{mg}$, iron $-9.6 \mathrm{mg}$, manganese $-2.9 \mathrm{mg}$. Microbiological studies have confirmed the compliance of the safety indicators of the developed additive with current requirements and sanitary standards Using frozen semifinished products from Salicornia, the technology of salted curd masses with high organoleptic characteristics has been developed. Promising areas of application of Salicornia in food technologies have been formulated. It is proposed to use a dietary supplement to create food products and optimize the diet of the population in order to enrich with substances of plant origin, mineral elements, biologically active substances, to prevent and maintain the functional activity of the human body.
\end{abstract}

Keywords: Salicornia Europaea L., food technologie, nutrients.

\section{Introduction}

To date, the world has not resolved the problems associated with the provision of food and guaranteed availability of safe and high-quality food products for everyone. A healthy, nutritious diet is important to health. Eating an excessive amount of carbohydrates and fats, an acute deficiency of minerals and vitamins lead to metabolic disorders. The population of many countries is experiencing a deficiency of essential nutrients, in particular, macro- and microelements - calcium, magnesium, phosphorus, iodine, iron, fluorine, selenium.

It is important and timely to use wild plant raw materials in nutrition, which is not used at all or is used to an incomplete extent. Research on plants has intensified to determine whether they can be used as potential nutraceuticals. Over the past ten years, it has been recognized that a number of little-known plants, in particular Salicornia (family

\footnotetext{
* Corresponding author: nvmurlykina@ karazin.ua
} 
Chenopodiaceae), are a valuable source of nutrients [1]. This halophyte grows on highly saline soils of the sea coasts, the shores of salt lakes, in gullies and ravines, that is, in fact, on most alkaline plains [2]. Salicornia has a geographical distribution spanning 4 continents such as Europe, Asia, Africa and North America. The Salicornioideae family comprises approximately 15 genera and 80 species [2]. The Salicornia species are: Salicornia (S.) herbacea (syn. to uropeae), S. indica (syn. to arthrocenemum), S. bigelovii, S. perenis, S. disarticulate.

The publications [3-6] provide information on the chemical composition of S. herbacea L. Its roots and stems contain alkaloids, choline, betaine, ascorbic acid, flavonoids, anthocyanins, beta-cyanidin, oxalates, amino acids, saponins, fatty acids, magnesium, potassium, sodium, iodine, bromine, etc.

Analysis of monosaccharides of the Salicornia brachiata fraction revealed a significant content of rhamnose, arabinose, mannose, galactose, and glucose with an insignificant presence of ribose and xylose [7]. Also found high protein content in seeds [8]. The lipid composition of S. ramosissima includes esterified and free fatty acids, fatty alcohol, sterols, alkanes and aromatic acid derivatives (free fatty acids, fatty alcohol, sterols, alkanes and aromatic acid derivatives). Palmitic acid, tetracosanol, and octacosanol play a significant role among the dominant components [9]. The presence of selenium was found in $\mathrm{S}$. brachiata [10]. S. herbacea seed oil is stable to oxidation and suitable for use in food processing [11]. Oil, which triacylglycerols contain linoleic, oleic, arachinic, palmitic acids, tocopherol $(\alpha, \gamma, \delta$-type), phenol, chlorophyll and $\beta$-carotene, and did not become rancid during 60 days of dark storage period [11].

A study [3] shows that the leaves of S. herbacea L. have a high level of moisture and a low level of total sugar, while the content of crude protein and lipids in the stem and root is similar. The content of raw ash and salt (dry basis) in the leaves exceeds that in the stem and root. The total amino acid content in the leaf, stem and root was 1270, 1525, and 1569 $\mathrm{mg} / 100 \mathrm{~g}$, respectively. Although the amino acid composition was different, their main amino acids were glutamic acid, leucine, isoleucine, and aspartic acid. Leaves, stems and roots were rich in $\mathrm{Na}, \mathrm{K}$ and $\mathrm{Ca}$.

Modern publications extensively highlight the antioxidant, antimicrobial, antiproliferative and anti-inflammatory activities of $\mathrm{S}$. herbacea extracts. Of these, quercetin 3-o-glucoside and isorhamnetin 3-o-glucoside were isolated and defined as active compounds of biological and pharmacological action [4]. An immunomodulatory polysaccharide was isolated from $\mathrm{S}$. herbacea $[12,13]$. An aliorative effect on the kidneys and liver was found, which correlated with a decrease in serum creatinine [14]. In addition, the activity of superoxide dismutase (SOD) and $\mathrm{Na}(+)-\mathrm{K}(+)$-ATPase increased, and the content of malonic dialdehyde (MDA) decreased, indicating a beneficial effect of this plant on the antioxidant profile of the body [14]. In another study [15], it was found that Salicornia bigelovii salt can be used to prevent the hypertensive effect that is commonly associated with sodium chloride.

Literature data indicate the use of S. herbacea L. as a raw material for food products [6, $11,16-18]$. As a raw material, Salicornia is used in the manufacture of drinks such as nuruk (a type of fermented sourdough), mcgeolli (Korean rice wine) or vinegar [16, 17]. Studies have shown that Salicornia not only stimulates the reproduction of microorganisms that support fermentation processes, but also improves the quality of vinegar [18].

In addition to direct consumption, these plants have been found suitable as a source of salt. S. herbacea powder was converted into spherical granules, which showed the potential for use as sodium chloride [19]. The study showed that $1.5 \%$ of Salicornia salt as a partial substitute for sodium chloride can be added to sausages to improve texture without any noticeable side effects [17]. The positive effect of fortification of Salicornia products was manifested in increasing the efficiency of yeast and stabilizing emulsions [17]. 
Thus, Salicornia is a source of valuable nutrients, among which there are those that determine the valuable functional and technological properties and organoleptic characteristics in the finished products with it. Important for the creation of new foods with Salicornia are emulsifying properties (emulsion stabilization), improved texture, salty taste, color formation (green color due to natural dyes), increasing the efficiency of yeast (stimulates the reproduction of microorganisms that support fermentation processes). The plant of the species Salicornia Europaea L. is one of the most salt-resistant species on the coast of the Sea of Azov (Ukraine) and can become a promising non-traditional plant raw material in Ukraine. Therefore, research on the creation of a dietary supplement based on Salicornia Europaea L. and its use in food technology and diets is relevant.

\section{Experimental}

Materials. Aerial parts of a plant of the species Salicornia Europaea L. (Fig. 1), collected in the south of the Kherson region, Ukraine, in August-October 2020, were taken as samples for the study.

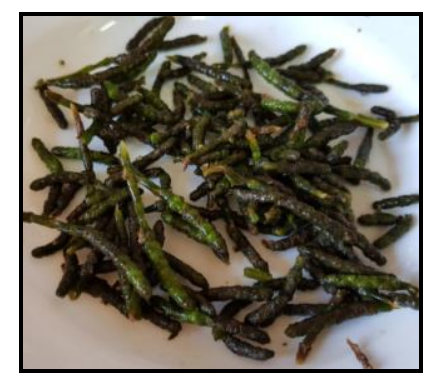

Fig. 1. The appearance of the aerial part of a plant of the species Salicornia Europaea L.

The aerial parts of a plant of the species Salicornia Europaea L. were used for the manufacture of a new dietary supplement "SoleVit Mg", samples of semi-finished products from the blanched aerial part of plants and blanched frozen aerial part of plants, frozen aerial part of plants.

Sampling. Sample preparation for research included thorough washing of the collected aerial part of a plant of the species Salicornia Europaea L. to remove sand. Then the washed and dried aerial parts of the plant were used to obtain the dietary supplement "SoleVit Mg", samples of semi-finished products from the blanched aerial part of plants and the blanched frozen aerial part of plants, as well as samples of the frozen aerial part of plants.

The main operations of the SoleVit $\mathrm{Mg}$ dietary supplement production technology included drying and grinding. Drying of plant samples of the aboveground part was carried out by one of the most common methods - convective, since its technological features allow preserving the properties of the original product. Drying temperatures of 95 and 75 ${ }^{\circ} \mathrm{C}$ are selected based on the requirements for organoleptic indicators, namely, color. Samples dried at these parameters had a color ranging from light beige to greenish. Grinding was carried out using a grinding mill to a particle size of the main fraction of 30$50 \mu \mathrm{m}$. The appearance of the label for packaging and dietary supplement "SoleVit Mg" is shown in Fig. 2, 3.

Frozen semi-finished products based on the aerial part of the Salicornia Europaea plant were prepared with and without preliminary blanching. The blanching of the samples from the aboveground part was carried out in a $1.0 \%$ citric acid solution for 10-15 min. Shock freezing of the samples was carried out to a temperature of $25^{\circ} \mathrm{C}$. Frozen semi-finished products were stored for 3-6 months. 


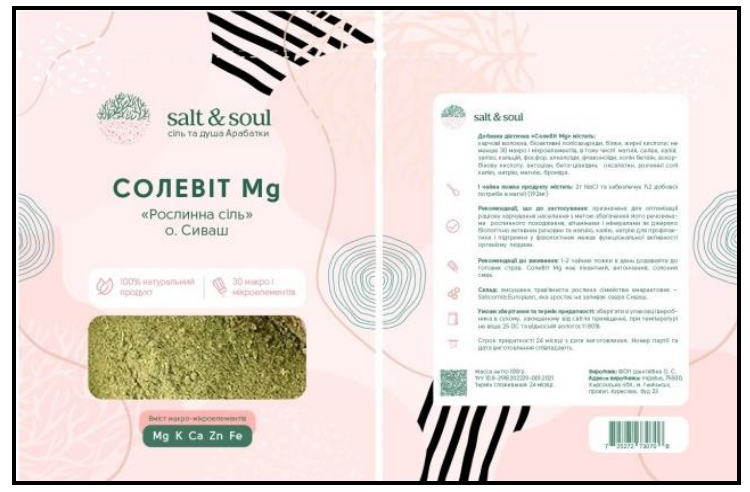

Fig. 2. Appearance of the label of the dietary supplement "SoleVit Mg"

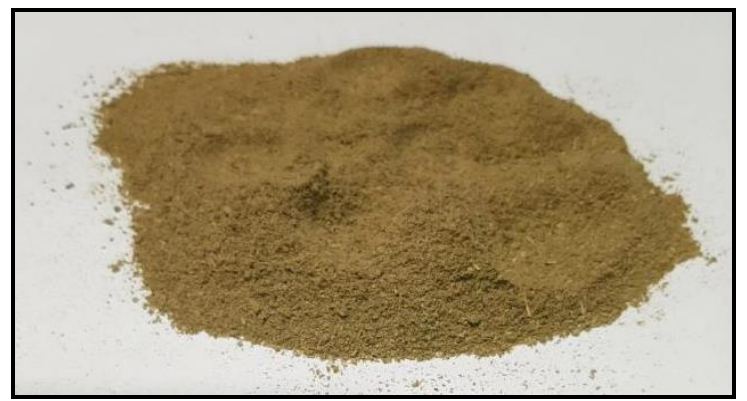

Fig. 3. Appearance of the dietary supplement "SoleVit Mg"

A traditional formulation was used to prepare samples of control of the mass of curd salted cheese. Samples of new curd salted masses were made using the SoleVit Mg dietary supplement, as well as semi-finished products based on the frozen blanched aerial part of Salicornia Europaea. The recipe composition of the salted curd mass with herbal additives containing chlorides and without additives (control) included $100 \mathrm{~g}$ of curd with a fat content of $9 \%$. Based on the traditional recipe and the recommended salt content $-10 \mathrm{~g}$ of salt per $1000 \mathrm{~g}$ of cottage cheese with a fat content of $9 \%$, as well as the content of chlorides in the studied herbal supplements, their weight was calculated per $100 \mathrm{~g}$ of cottage cheese, which was 6 for the dietary supplement "SoleVit Mg", 3 g, semi-finished products based on frozen blanched aerial plant parts $-50 \mathrm{~g}$.

The technology of salted curd mass with frozen semi-finished product based on the blanched aerial part of Salicornia Europaea included the following operations:

- homogenization of unfrozen semi-finished products based on the aerial part of Salicornia Europaea (Fig. 4);

- homogenization of curd $9 \%$;

- mixing prepared curd 9\% and unfrozen semi-finished products based on the blanched aerial part of Salicornia Europaea and obtaining a finished product (Fig. 5). 


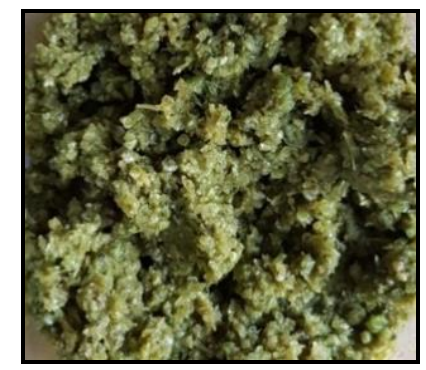

Fig. 4. Appearance of semi-finished products based on frozen blanched aerial plant parts after homogenization.

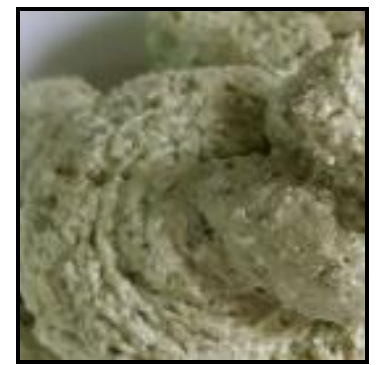

Fig. 5. Appearance of salted curd mass with frozen semi-finished product based on blanched aerial part of Salicornia Europaea.

The technology of making a salted curd mass with a dietary supplement "SoleVit Mg" (Fig. 6) included the operation of homogenizing curd $9 \%$ and mixing it with a dietary supplement "SoleVit Mg".

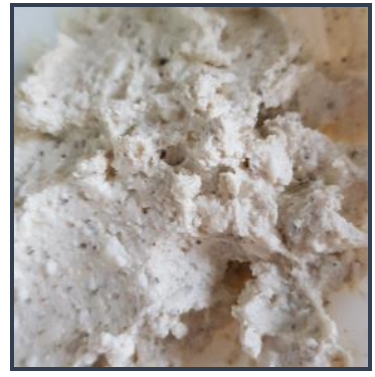

Fig. 6. Appearance of the salted curd mass with a dietary supplement "SoleVit Mg".

Methods. Determination of solid matter and moisture in the dietary supplement "SoleVit $\mathrm{Mg}$ " and samples of the aerial part of Salicornia Europaea was carried out by standard methods. Total protein was determined by the Kjeldahl method, crude fat - in a Soxhlet apparatus, ash - by ashing. The energy value of the dietary supplement and semi-finished product is obtained by calculation.

The mineral composition of the samples was determined by arc-excited atomic emission spectroscopy (AC arc) on a DFS-8 spectrometer. The content of organic iodine was determined by coulometric titration. The content of chloride ions in the composition of the samples of the aerial part and the dietary supplement was determined titrimetrically according to the standard method.

Vitamins $\mathrm{B}_{1}, \mathrm{~B}_{2}, \mathrm{~B}_{6}, \mathrm{~B}_{\mathrm{C}}, \mathrm{PP}$ were determined by high performance liquid chromatography, $\mathrm{B}_{4}-$ colorimetric method, Vitamin $\mathrm{C}$ - titrimetrically with 2,6dichlorophenolindophenol. Determination of vitamin A was carried out colorimetrically, $\beta$ -carotene - spectrophotometrically from one extract after their separation on the same column with aluminum oxide.

The total antioxidant capacity for the aerial samples of Salicornia Europaea was determined by coulometric titration with electrogenerated bromine.

Microbiological indicators were determined by standard methods to identify the presence of pathogenic microorganisms in them. 


\section{Results and discussion}

The first stage of research of plant samples of Salicornia Europaea and dietary supplement "SoleVit Mg", made on their basis, included the determination of the total chemical, vitamin and mineral composition, as well as microbiological studies.

The results of an experimental study of the total chemical composition of the aerial part of Salicornia Europaea and the dietary supplement "SoleVit Mg" are given in Table 1. The mass fraction of solid matter was $11.8 \pm 0.30$ and $94.70 \pm 1.21 \%$, respectively, protein $2.24 \pm 0.02$ and $22.10 \pm 0.8 \%$, fat $-0.27 \pm 0,01$ and $2.65 \pm 0.21 \%$, carbohydrates $-3.19 \pm 0.02$ and $31.50 \pm 0.75 \%$, ash $-6.10 \pm 0.01$ and $38.45 \pm 0.01 \%$

Table 1. Results of determining the total chemical composition of samples based on Salicornia Europaea.

\begin{tabular}{|c|c|c|c|c|c|c|}
\hline \multirow{2}{*}{ Sample name } & \multicolumn{5}{|c|}{ Mass fraction, $\%$} & \multirow{2}{*}{$\begin{array}{l}\text { Calorie content } \\
\text { per } 100 \mathrm{~g} \text { of } \\
\text { product, kcal } \\
\text { (energy value, } \\
\text { kJ) }\end{array}$} \\
\hline & $\begin{array}{l}\text { Solid } \\
\text { matter }\end{array}$ & Proteins & Fats & $\begin{array}{c}\text { Carbohydr } \\
\text { ates }\end{array}$ & Ash & \\
\hline $\begin{array}{l}\text { Aerial part of } \\
\text { Salicornia Europaea }\end{array}$ & $11,80 \pm 0,30$ & $2,24 \pm 0,02$ & $0,27 \pm 0,01$ & $3,19 \pm 0,02$ & $6,10 \pm 0,01$ & $\begin{array}{l}24,15 \pm 0,50 \\
(101,2 \pm 1,2)\end{array}$ \\
\hline $\begin{array}{l}\text { Dietary supplement } \\
\text { "SoleVit Mg" }\end{array}$ & $94,70 \pm 1,21$ & $22,10 \pm 0,8$ & $2,65 \pm 0,21$ & $31,50 \pm 0,75$ & $38,45 \pm 0,01$ & $\begin{array}{c}238,25 \pm 3,50 \\
(998,3 \pm 1,2)\end{array}$ \\
\hline
\end{tabular}

The vitamin profile of the aerial samples of Salicornia Europaea shown in Table 2 included vitamins $B_{1}(0.013 \mathrm{mg} / 100 \mathrm{~g}), \mathrm{B}_{2}(0,010 \mathrm{mg} / 100 \mathrm{~g}), \mathrm{B}_{4}(0,39 \mathrm{mg} / 100 \mathrm{~g}), \mathrm{B}_{6}(0,030$ $\mathrm{mg} / 100 \mathrm{~g}), \mathrm{PP}(0,29 \mathrm{mg} / 100 \mathrm{~g}), \mathrm{B}_{\mathrm{c}}(0,002 \mathrm{mg} / 100 \mathrm{~g}), \mathrm{C}(1,25 \mathrm{mg} / 100 \mathrm{~g}), \beta$-каротин $(0,068$ $\mathrm{mg} / 100 \mathrm{~g}), \mathrm{A}(0,01 \mathrm{mg} / 100 \mathrm{~g})$.

Table 2. Results of determining the vitamin composition of plant samples from the aerial part of Salicornia Europaea.

\begin{tabular}{|c|c|c|c|c|c|c|c|c|c|}
\hline \multirow{2}{*}{ Sample name } & \multicolumn{9}{|c|}{ Content, mg/100 g } \\
\cline { 2 - 10 } & $\mathbf{B}_{\mathbf{1}}$ & $\mathbf{B}_{\mathbf{2}}$ & $\mathbf{B}_{\mathbf{4}}$ & $\mathbf{B}$ 6 & $\mathbf{P P}$ & $\mathbf{B} \mathbf{C}$ & $\mathbf{C}$ & $\begin{array}{c}\boldsymbol{\beta} \text { - } \\
\text { carotene }\end{array}$ & $\mathbf{A}$ \\
\hline $\begin{array}{c}\text { Aerial part of } \\
\text { Salicornia Europaea }\end{array}$ & 0,013 & 0,010 & 0,39 & 0,030 & 0,29 & 0,002 & 1,25 & 0,068 & 0,010 \\
\hline
\end{tabular}

The research results indicate that the ash residue of the samples based on Salicornia Europaea is represented by both macro- and microelements (Table 3).

In the samples of the aerial part of Salicornia Europaea, the content of macronutrients was: sodium - $549 \mathrm{mg} / 100 \mathrm{~g}$ ), potassium - $183 \mathrm{mg} / 100 \mathrm{~g}$, magnesium $-122 \mathrm{mg} / 100 \mathrm{~g}$, calcium - $92 \mathrm{mg} / 100 \mathrm{~g}$, phosphorus $-103 \mathrm{mg} / 100 \mathrm{~g}$. Microelements were represented by silicon $(12.7 \mathrm{mg} / 100 \mathrm{~g})$, zinc $(1.8 \mathrm{mg} / 100 \mathrm{~g})$, iron $(1.5 \mathrm{mg} / 100 \mathrm{~g})$, magnesium $(0.5$ $\mathrm{mg} / 100 \mathrm{~g})$, copper $(0.4 \mathrm{mg} / 100 \mathrm{~g})$, etc.

It should be noted that the created dietary supplement "SoleVit $\mathrm{Mg}$ " is a source of such macronutrients as sodium $(3460 \mathrm{mg} / 100 \mathrm{~g})$, potassium $(1155 \mathrm{mg} / 100 \mathrm{~g})$, magnesium $(770$ $\mathrm{mg} / 100 \mathrm{~g})$, calcium $(580 \mathrm{mg} / 100 \mathrm{~g})$ and phosphorus $(650 \mathrm{mg} / 100 \mathrm{~g})$ and trace elements silicon $(80 \mathrm{mg} / 100 \mathrm{~g})$, zinc $(11.5 \mathrm{mg} / 100 \mathrm{~g})$, iron $(9.6 \mathrm{mg} / 100 \mathrm{~g})$, magnesium $(2.9 \mathrm{mg} / 100$ $\mathrm{g})$, copper $(2.3 \mathrm{mg} / 100 \mathrm{~g})$. In addition, molybdenum $(0.38 \mathrm{mg} / 100 \mathrm{~g})$, nickel $(0.20$ 
$\mathrm{mg} / 100 \mathrm{~g})$, cobalt $(<0.03 \mathrm{mg} / 100 \mathrm{~g})$, conditionally essential strontium $(1.9 \mathrm{mg} / 100 \mathrm{~g})$ and other elements in an amount of $<0.01 \mathrm{mg} / 100 \mathrm{~g}$ (cadmium, arsenic, mercury).

Table 3. Results of determining the mineral composition of samples based on Salicornia Europaea.

\begin{tabular}{|c|c|c|c|c|c|c|c|c|c|c|c|c|c|c|c|}
\hline \multirow{2}{*}{$\begin{array}{c}\text { Sample } \\
\text { name }\end{array}$} & \multicolumn{10}{|c|}{ Element content, mg/100 g sample } \\
\cline { 2 - 13 } & $\mathbf{F e}$ & $\mathbf{S i}$ & $\mathbf{P}$ & $\mathbf{A l}$ & $\mathbf{M n}$ & $\mathbf{M g}$ & $\mathbf{P b}$ & $\mathbf{N i}$ & $\mathbf{M o}$ & $\mathbf{C a}$ & $\mathbf{C u}$ & $\mathbf{Z n}$ & $\mathbf{N a}$ & $\mathbf{K}$ & $\mathbf{S r}$ \\
\hline $\begin{array}{c}\text { Aerial part } \\
\text { of Salicornia } \\
\text { Europaea }\end{array}$ & 1,5 & 12,7 & 103 & 1,8 & 0,5 & 122 & - & 0,03 & 0,1 & 92,0 & 0,4 & 1,8 & 549 & 183 & 0,3 \\
\hline $\begin{array}{c}\text { Dietary } \\
\text { supplement } \\
\text { "SoleVit Mg" }\end{array}$ & 9,6 & 80 & 650 & 11,5 & 2,9 & 770 & - & 0,20 & 0,38 & 580 & 2,3 & 11,5 & 3460 & 1155 & 1,9 \\
\hline
\end{tabular}

The content of organic iodine, determined in the dietary supplement "SoleVit Mg" by the coulometric titration method, was $43 \mu \mathrm{g} / 100 \mathrm{~g}$. The content of chloride ions in the samples of the aboveground part and the dietary supplement "SoleVit Mg" were respectively $1.28 \mathrm{~g} / 100 \mathrm{~g}$ and $10.53 \mathrm{~g} / 100 \mathrm{~g}$.

Antioxidant properties were also studied for samples from the aerial part of the plant. The total antioxidant capacity was $9 \mathrm{mg}$ gallic acid equivalent per $100 \mathrm{~g}$ of product.

In the course of the conducted microbiological studies (Table 4), it was found that bacteria of the Escherichia coli group and pathogenic microorganisms were absent, respectively, in 0.001 and $25 \mathrm{~g}$ of samples of freshly prepared semi-finished products, and the amount of MAFAnM in $1 \mathrm{~g}$ of the sample was $1 \cdot 10^{5}$ and did not exceed the established norms. That is, the microbiological indicators of the dietary supplement "SoleVit Mg" comply with the current requirements and sanitary standards.

Table 4. Microbiological indicators of the dietary supplement "SoleVit Mg".

\begin{tabular}{|l|c|c|}
\hline \multicolumn{1}{|c|}{ Indicator name } & $\begin{array}{c}\text { Allowable level, no } \\
\text { more }\end{array}$ & Actual value \\
\hline $\begin{array}{l}\text { Number of Mesophilic Aerobic and Facultative } \\
\text { Anaerobic Microorganisms CFU in 1 g, no more }\end{array}$ & $5 \cdot 10^{5}-1 \cdot 10^{6}$ & $1 \cdot 10^{4}$ \\
\hline Escherichia coli bacteria (coli-forms) in 0.1 g & Not allowed & Not found \\
\hline Escherichia coli в 1,0 г & Not allowed & Not found \\
\hline Stapylococcus aureus, в 1,0 г & Not allowed & Not found \\
\hline $\begin{array}{l}\text { Pathogenic microorganisms, including bacteria of } \\
\text { the genus Salmonella, in } 10 \mathrm{~g} \text { of product }\end{array}$ & Not allowed \\
\hline Mold fungi, CFU in 1.0 g, no more & $1 \cdot 10^{3}$ & $3 \cdot 10^{2}$ \\
\hline Yeast, CFU in 1.0 g, no more & $1 \cdot 10^{2}$ & $0,1 \cdot 10$ \\
\hline B. cereus, CFU, в 1.0 g, no more & $1 \cdot 10^{2}$ & $0,2 \cdot 10$ \\
\hline
\end{tabular}

Studies have confirmed that the plant samples of Salicornia Europaea and the dietary supplement "SoleVit Mg" contain all groups of basic nutrients - proteins, fats and 
carbohydrates, are a source of valuable vitamins and minerals, and have antioxidant activity. Therefore, they can be used in food technologies as raw materials, and products with them - for the prevention and maintenance of the functional activity of the human body within the physiological limits. The increased content of sodium chloride allows the use of additives as a partial substitute for table salt in food products.

The next step was to study the organoleptic characteristics of salted curd masses developed using the dietary supplement "SoleVit Mg" (sample 1) and semi-finished products based on the frozen blanched aerial part of Salicornia Europaea (sample 2). Preliminary tests have shown that the samples from the frozen aerial part of plants are significantly inferior in their organoleptic characteristics to the samples from the blanched frozen aerial part. Namely, they had an almost lost green color, a damaged and significantly softened structure of plant fibers, a large loss of intracellular bound moisture and its high separation. Therefore, in the future, they were not used to make samples of salted curd mass. The results of the sensory evaluation of new masses of curds with Salicornia Europaea are given in Table 5.

Table 5. Organoleptic indicators of the salted curd mass with Salicornia Europaea.

\begin{tabular}{|c|l|c|c|}
\hline \multirow{2}{*}{ Indicator name } & \multicolumn{1}{|c|}{ Characteristic } & \multicolumn{2}{|c|}{ Assessment, points } \\
\cline { 3 - 4 } & & 5,0 & 5,0 \\
\hline Appearance & Formed curd products of various shapes & Sample 2 \\
\hline Consistence & $\begin{array}{l}\text { Homogeneous, gentle, moderately dense. The } \\
\text { presence of particles of used fillers (Salicornia } \\
\text { Europaea), soft cheese grains, light powdery }\end{array}$ & 5,0 & 5,0 \\
\hline Color & $\begin{array}{l}\text { Gentle green or light beige, due to the color of the } \\
\text { injected filler (Salicornia Europaea) }\end{array}$ & 5,0 & 5,0 \\
\hline Taste and odor & $\begin{array}{l}\text { Characteristic fermented milk, moderately salty, with } \\
\text { a taste inherent in the corresponding filler (Salicornia } \\
\text { Europaea) }\end{array}$ & 5,0 & 4,8 \\
\hline
\end{tabular}

Salted curd masses with the dietary supplement "SoleVit Mg", as well as with a semifinished product based on frozen blanched aerial plant parts, were distinguished by high organoleptic characteristics.

Analytical studies highlighting the composition and properties of Salicornia Europaea, as well as experimental studies of additives from the aerial part of the Salicornia Europaea plant and food products with them, made it possible to identify promising areas of application of the SoleVit $\mathrm{Mg}$ dietary supplement and semi-finished products based on Salicornia Europaea. A diagram showing possible applications is shown on Fig. 7. 


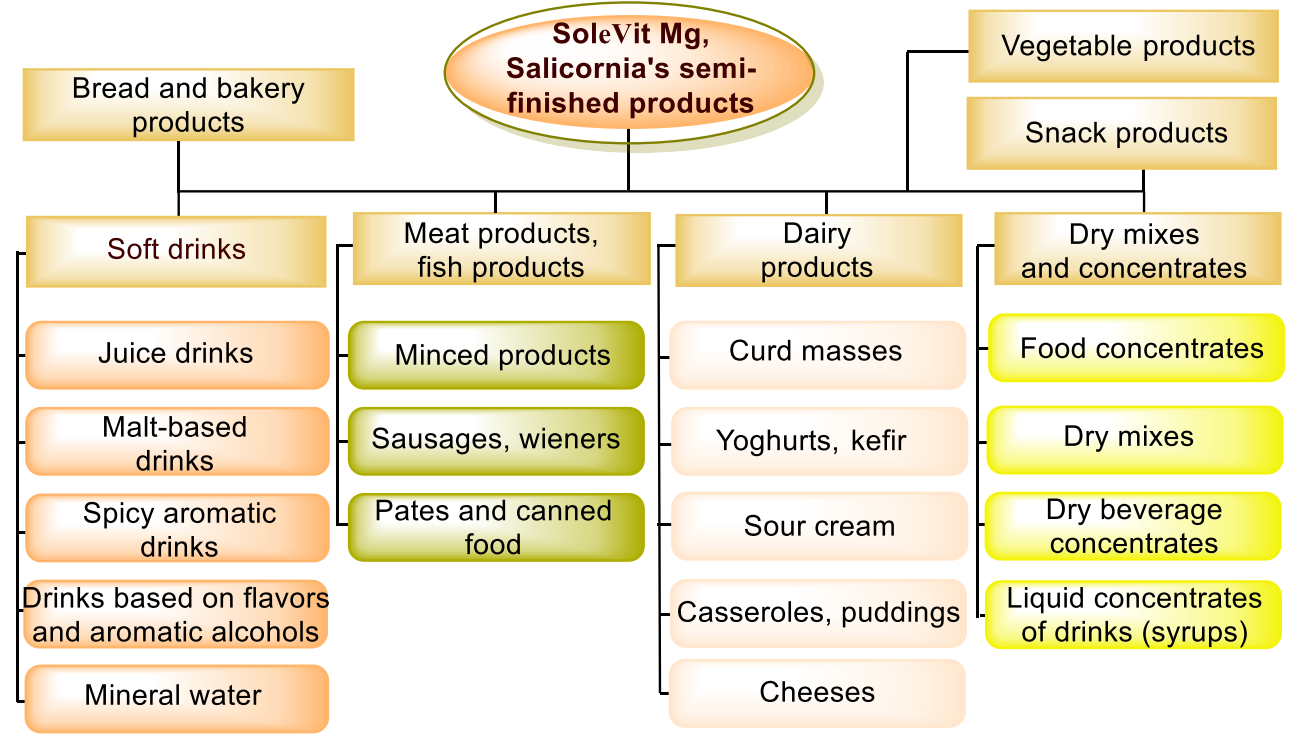

Fig. 7. Promising areas of application of the dietary supplement "SoleVit Mg" and semifinished products based on the aerial part of the plant Salicornia Europaea.

Considering that plants of the Salicornia Europaea L. species are a source of valuable nutrients and contain compounds that determine emulsifying properties, texture, color, taste-forming abilities important for the creation of new food products, stimulate the reproduction of microorganisms that support fermentation processes, the main promising areas of their use there will be technologies for bread and bakery, meat and fish products, dairy products, vegetables and snacks, dry mixes and concentrates, soft drinks.

\section{Conclusion}

On the basis of the aboveground part of the plant samples of Salicornia Europaea, a dietary supplement "SoleVit Mg" and frozen semi-finished products for use in food technologies have been developed and manufactured.

It has been experimentally confirmed that the plant samples of Salicornia Europaea and the dietary supplement "SoleVit Mg" contain all groups of basic nutrients - proteins, fats and carbohydrates, are a source of valuable vitamins (choline, nicotinic acid, vitamin $\mathrm{C}, \beta$ carotene, etc.) and mineral elements $(\mathrm{Mg}, \mathrm{Ca}, \mathrm{K}, \mathrm{Fe})$, have antioxidant activity.

Microbiological studies have confirmed the compliance of the safety indicators of the developed additive and semi-finished products with the current requirements and sanitary standards.

Salted curd masses have been developed with the dietary supplement "SoleVit Mg", as well as with a semi-finished product based on frozen blanched aerial parts of Salicornia Europaea plants, characterized by high organoleptic characteristics.

On the basis of analytical and experimental studies, promising directions for the use of Salicornia Europaea in food technologies have been identified and formulated.

The dietary supplement "SoleVit Mg" and semi-finished products based on the aerial part of Salicornia Europaea are promising for creating food products and optimizing the diet of the population in order to enrich with substances of plant origin, mineral elements, biologically active substances, for the prevention and maintenance of the functional activity of the human body within the physiological limits. 


\section{References}

1. D. Singh, A. K. Buhmann, T. Flowers, C. E. Seal, J. Papenbrock, AoB Plants 6, plu071 (2014)

2. C. Smillie, Ecological Indicators 56 (2015)

3. J. G. Min, D. S. Lee, T. J. Kim, J. H. Park, Preventive Nutrition and Food Sci. 7, 1 (2002)

4. 2 M. H. Rhee, H. J. Park, J. Y. Cho, J. of medicinal plant research 3, 8 (2009)

5. I. Cybulska, T. Chaturvedi, A. Alassali, G. P. Brudecki, J. J. Brown, S. Sgouridis, M. H. Thomsen, Energy Fuels 28, 6 (2014)

6. M. Tabarsa, M. Rezaei, Z. Ramezanpour, J. R. Waaland, J. Sci. Food and Agric. 92,12 (2012)

7. N. D. Sanandiya, A. K. Siddhanta, Carbohyd. Polym. 112 (2014)

8. B. Jha, N. P. Singh, A. Mishra, J. Agric. Food Chem. 60 (2012)

9. V. M. S. Isca, A. M. L. Seca, C. G. A. Pinto, H. Silva, A. M. S. Silva, Food Chem. 165 (2014)

10. A. Mishra, M. K. Patel, B. Jha, J. Funct. Foods 13 (2015)

11. D. Choi, G. S Lim, Y. L. Piao, et al., Korean J. Chem. Eng. 31 (2014)

12. K. Y. Lee, M. H. Lee, I. Y. Chang, et al. J. Ethnopharmacol. 103 (2006)

13. S. A. Im, K. Kim, C. K Lee, Int. Immunopharmacol. 6 (2006)

14. S. Zhang, M. Wei, C. Cao, et al. Food Funct. 6 (2015)

15. S. Patel, 3 Biotech 6, 104 (2016)

16. S. H. Song, C. Lee, S. Lee, et al. J. Microbiol. Biotechnol. 23 (2013)

17. H. W Kim, K. E Hwang, D. H Song, et al. Meat Sci. 97 (2014)

18. H. Seo, B. Y. Jeon, A.Yun, D. H. Park, J. Microbiol. Biotechnol. 20 (2010)

19. M. G Shin, G. H Lee, Prev. Nutr. Food Sci. 18 (2013) 